\title{
ESTADO DA ARTE SOBRE EDUCAÇÃO E RELAÇÕES ÉTNICO-RACIAIS (2003-2014): HISTÓRIA DA EDUCAÇÃO DE CRIANÇAS E JOVENS NEGROS(AS)
}

\author{
Marcelo Pagliosa Carvalho*
}

\section{RESUMO}

A Categoria "História da Educação da População Negra" da pesquisa "Educação e Relações Étnico-Raciais: o Estado da Arte" (2018) abrangeu a análise de 35 teses e dissertações. Neste artigo serão examinados os pormenores das 17 pesquisas agrupadas na subcategoria "Educação de crianças e jovens negros(as)". Observou-se que a temática da História da Educação da População Negra é uma área em construção, mas em expansão, apesar da necessidade de um número maior de pesquisas.

Palavras-chave: história da educação da população negra, história da educação, história e cultura africana e afro-brasileira.

\footnotetext{
${ }^{*}$ Universidade Federal do Maranhão (UFMA), São Luis/MA, Brasil.
} 


\title{
ESTADO DEL ARTE EN EDUCACIÓN Y RELACIONES ÉTNICO-RACIALES (2003-2014): HISTORIA DE LA EDUCACIÓN DE NIÑOS Y JÓVENES NEGROS
}

\section{RESUMEN}

La categoría "Historia de la educación de la población negra" de la investigación "Educación y relaciones étnico-raciales: el estado del arte" (2018) abarcó el análisis de 35 tesis y disertaciones. En este artículo se examinarán los detalles de las 17 encuestas agrupadas en la subcategoría "Educación de niños y jóvenes negros". Se observó que el tema de la Historia de la Educación de la Población Negra es un área en construcción, pero en expansión, a pesar de la necesidad de un mayor número de investigaciones.

Palabras clave: historia de la educación de la población negra, historia de la educación, historia y cultura africana y afrobrasileña.

\section{STATE OF THE ART ON EDUCATION AND ETHNIC- RACIAL RELATIONS (2003-2014): HISTORY OF THE EDUCATION OF BLACK CHILDREN AND YOUTH}

\begin{abstract}
The "History of the Education of the Black Population" Category of the research "Education and Ethnic-Racial Relations: the State of the Art" (2018) covered the analysis of 35 theses and dissertations. In this article, the details of the 17 surveys grouped in the subcategory "Education of black children and young people" will be examined. It was observed that the theme of the History of Education of the Black Population is an area under construction, but expanding, despite the need for a greater number of researches.
\end{abstract}

Keywords: history of black population education, history of education, african and afrobrazilian history and culture.

\section{ETAT DE L'ART SUR L'ÉDUCATION ET LES RELATIONS ENTRE ETHNIES ET RACES (2003-2014): HISTORIQUE DE L'ÉDUCATION DES ENFANTS ET DES JEUNES NOIRS}

\section{RÉSUMÉ}

La catégorie "Histoire de l'éducation de la population noire" de la recherche "Éducation et relations ethno-raciales: l'état de l'art" (2018) a couvert l'analyse de 35 thèses et mémoires. Dans cet article, les détails des 17 enquêtes regroupées dans la sous-catégorie "Education des enfants et des jeunes noirs" seront examinés. On a observé que le thème de l'histoire de l'éducation de la population noire est un domaine en construction, mais en expansion, malgré la nécessité d'un plus grand nombre de recherches.

Mots-clés: histoire de l'éducation de la population noire, histoire de l'éducation, histoire et culture africaines et afro-brésiliennes. 


\section{INTRODUÇÃO}

Este artigo objetiva perscrutar dados quantitativos dos 35 trabalhos discentes (teses e dissertações), sobretudo os pormenores dos 17 estudos agrupados na subcategoria "Educação de crianças e jovens negros(as)", que foram reunidos na Categoria "História da Educação da População Negra" da Pesquisa "Educação e Relações Étnico-Raciais: o Estado da Arte" (SILVA; REGIS; MIRANDA, 2018), surgida a partir da proposição do Grupo de Trabalho em Educação e Relações Étnico-Raciais (GT 21) da Associação Nacional de PósGraduação e Pesquisa em Educação (ANPED)1. Em seu processo de construção do projeto e de desenvolvimento, o Estado da Arte abarcou a ABPN (Associação Brasileira de Pesquisadores Negros) e o Conneab (Consórcio Nacional de Núcleos de Estudos Afro-Brasileiros). Obteve-se financiamento para a execução pela Secadi/MEC (Secretaria de Educação Continuada, Alfabetização, Diversidade e Inclusão do Ministério da Educação), apoio institucional da UFMG, UFMA e $\mathrm{UFPR}^{2}$ - por meio dessa última se teve o aporte de financiamentos complementares, sobretudo de bolsas de iniciação científica de cota do NEABUFPR do Programa Institucional de Apoio à Inclusão Social - Pesquisa e Extensão Universitária da Fundação Araucária de Apoio Científico e Tecnológico do Estado do Paraná.

A Pesquisa "Educação e Relações Étnico-Raciais: o Estado da Arte" objetivou mapear e sintetizar a produção acadêmica sobre educação e relações étnico-raciais entre 2003 e 2014, no Brasil, por meio da leitura de teses e dissertações realizadas nos Programas de pós-graduação stricto sensu em Educação, bem como de artigos publicados em periódicos Qualis A e B na área da Educação, e de livros produzidos pelos Núcleos de Estudos Afro-Brasileiros (NEABs) e grupos correlatos. A Pesquisa selecionou e analisou 494 artigos, 476

\footnotetext{
${ }^{1}$ Para esse Estado da Arte também foram selecionados e analisados artigos escritos em periódicos da área da educação (2003-2014). Seus resultados foram publicados em Educar em Revista (2018).

2 As universidades responsáveis em coordenar o Estado da Arte foram escolhidas pelo GT-21 da ANPED, durante a $37^{\mathrm{a}}$ Reunião Nacional dessa Associação, devido à expertise na área.
} 
dissertações e 122 teses da área de educação.

Dentre os objetivos específicos previamente definidos, destaque para: a) Identificar e sistematizar a produção acadêmica sobre educação e relações étnicoraciais; b) Identificar e categorizar as temáticas recorrentes; c) Averiguar quais são as abordagens teóricas e metodológicas dominantes3; d) Verificar quais são as temáticas emergentes e as lacunas nesta produção; e) Examinar as críticas e proposições ao ensino da História e Cultura africana e dos negros brasileiros nas instituições escolares realizadas pela produção acadêmica da área; f) Sistematizar as recomendações dos trabalhos analisados para a implementação da Lei $n^{0}$ 10.639/2003 (SILVA; REGIS; MIRANDA, 2018, p. 40).

Sua finalidade é contribuir no exame das repercussões da implantação e implementação da Lei $n^{0}$ 10.639/2003, que obriga a inclusão das Histórias e Culturas Africanas e Afro-Brasileiras nos currículos escolares, na produção científica brasileira. Segundo Gomes (2018, p. 16-17), na Apresentação dos resultados da Pesquisa,

[...] a produção acadêmica sobre relações étnico-raciais e educação ainda não havia sido objeto de um processo denso, organizado e sistematizado que incluísse uma análise do que tem sido produzido após a sanção da Lei 10.639/03. Faltava-nos uma investigação científica abrangente, em nível nacional, que pudesse verificar quais são os principais temas abordados, as problemáticas privilegiadas e pouco ou não estudadas, onde esta produção vem sendo realizada, que lugar ela ocupa na pós-graduação em educação, como se articula com as outras áreas do conhecimento, a circulação nacional e internacional dos estudos e pesquisas e quais são as autoras e os autores de renome nacional e internacional que inspiram as novas gerações de pesquisadores e pesquisadoras.

A equipe de investigação contou com a participação: 1) de

\footnotetext{
3 Vale destacar que, de acordo com a metodologia proposta no Estado da Arte, a Categoria em análise não ficou responsável em discutir subcategorias analíticas como raça, racismo, negritude, branquitude e colonialidade, uma vez que outras categorias da mesma Pesquisa as contemplariam.
} 
pesquisadoras(es) das três universidades responsáveis pela Pesquisa (UFMG, UFMA e UFPR4) e 2) e de outras instituições que foram convidadas(os) por causa da reconhecida atuação na área5. Tratou-se, portanto, de um trabalho conjunto de recolha de material, estudo, análise e reflexão concretizado por uma equipe de especialistas de diferentes Núcleos de Estudos Afro-Brasileiros (NEABs), vinculados à Associação Brasileira de Pesquisadores Negras e Negros (ABPN) e sob a coordenação de pesquisadores ligados ao GT 21, Educação e Relações Étnico-Raciais da ANPEd. O desafio colocado: realizar uma Pesquisa com tal magnitude sobre educação das relações étnico-raciais e trazer contribuições efetivas ao campo educacional.

Em relação à especificidade da Categoria analisada neste artigo ("História da Educação da População Negra”), é valioso mencionar que muitas(os) estudiosas(os) (GOMES; ARAÚJO, 2014; OLIVEIRA, 2004; ROSEMBERG, 2011) apontam lacunas ou falta de um número maior de pesquisas em História da Educação que se dediquem: ao entendimento das relações étnicoraciais; ao acesso e permanência da população negra nas unidades educacionais; às reivindicações históricas do Movimento Negro para a construção de uma educação brasileira antirracista e/ou com igualdade racial. Segundo Gomes (2018, p. 16-17), essa lacuna se conformava como uma grande perda para a produção do conhecimento de um modo geral e, em particular, para a educação ${ }^{6}$.

Pesquisadoras(es) da área destacam que o escopo da legislação em questão (Leis $\mathrm{n}^{0}$ 10.639/2003, $\mathrm{n}^{\mathrm{0}}$ 11.645/2008 e suas correlatas) demandam algo muito mais diverso e valioso do que o simples acréscimo de conteúdos: o combate

\footnotetext{
4 Paulo Vinicius Baptista da Silva (UFPR), Katia Regis (UFMA) e Shirley Aparecida de Miranda (UFMG) coordenaram o Estado da Arte. Demais pesquisadoras(es) das três universidades que fizeram a análise dos artigos, teses e dissertações das categorias: Lucimar Rosa Dias, Débora Cristina de Araujo e Valeria Milena Rohrich Ferreira (UFPR) e Marcelo Pagliosa (UFMA).

5 Petronilha Beatriz Gonçalves e Silva, Wilma de Nazaré Baía Coelho, Tânia Mara Pedroso Müller e Luiz Alberto Oliveira Gonçalves foram as(o) investigadoras de outras instituições que foram convidadas(o) e ficaram responsáveis em analisar as categorias da Pesquisa. Nilma Lino Gomes, ex-ministra da Secretaria Especial de Igualdade Racial, atuou como consultora e realizou a Apresentação dos resultados desse Estado da Arte.

${ }^{6}$ No que diz respeito à educação na infância e as relações étnico-raciais, o trabalho de Gomes e Araújo (2014) realiza uma importante latitude histórica.
} 
ao racismo e a conformação da memória histórica (COELHO; COELHO, 2018; MUNANGA, 2015). Como assevera Gomes (2012, p. 106), "trata-se, na realidade, de uma mudança estrutural, conceitual, epistemológica e política”, em um processo de descolonização do currículo (do poder e do saber), que implica conflito, confronto, negociações e produz algo novo, cujo resultado esperado se configura na construção de projetos educativos emancipatórios.

A inclusão das Histórias e Culturas Africanas e Afro-Brasileiras se relaciona com a democracia, com a inclusão de todos os sujeitos coletivos na história e nos direitos humanos. Silva (2015, p. 163-164) ressalta a importância dessa inclusão curricular no fortalecimento da autoestima das pessoas negras. Mais ainda, no dilema que essas pessoas, de modo contundente as crianças negras, têm de fazer face: ou deixar-se assimilar a ideias, crenças, comportamentos, admitindo "branquear" no pensamento, nos raciocínios, nos comportamentos, na adoção de projeto de sociedade que exclui os negros, ou enfrentar desqualificação ao mostrar, em gestos, palavras, iniciativas, sua negritude:

Como explicar às crianças negras e também às não negras que os afrodescendentes são os únicos brasileiros, pelo menos a significativa maioria deles, que desconhecem precisamente de onde vieram seus antepassados? Seus antepassados aprisionados, escravizados e para cá forçadamente transportados guardaram em usos, costumes e até mesmo na língua portuguesa, lembranças contundentes das suas culturas e sabedoria africanas. Mas sofrimentos causados pela desumanização de seus corpos e mentes, a separação e o isolamento de nativos de um mesmo povo, deixaram pistas remotas sobre região, vila, cidade de que eram originários. Tiveram, eles, que se reinventar como seres humanos, como africanos da Diáspora. Se essa situação constrange adultos, imagine-se o quanto interfere no fortalecimento da autoestima das crianças negras, também das outras, as não negras. Como ensinar que somos todos iguais, diante de tão forte desigualdade? Que cidadania poderão essas crianças construir?

O material dessa Categoria foi agrupado por similaridade de temas e dividido em quatro subcategorias: Educação de crianças e jovens negros(as); 
Lutas coletivas da população negra e educação; Docentes e/ou intelectuais negros(as): trajetórias profissionais e de vida; e Outros temas. Nesse artigo, entretanto, por causa da amplitude do material e do espaço circunscrito para a publicação nessa Revista, privilegiou-se o estudo descritivo dos trabalhos discentes que foram congregados na subcategoria "Educação de crianças e jovens negros(as)", justamente porque foi a que abarcou o maior número de pesquisas, no caso, 17 teses e dissertações.

\section{DADOS GERAIS DA CATEGORIA “HISTÓRIA DA EDUCAÇÃO DA POPULAÇÃO NEGRA"}

Antes de iniciarmos as análises de conteúdo de cada um dos trabalhos discentes da subcategoria "Educação de crianças e jovens negros(as)", vamos aos números gerais da Categoria "História da Educação da População Negra" (Tabela 1):

Tabela 1 - Distribuição temporal das 35 teses e dissertações.

\begin{tabular}{c|c}
\hline ANO & $\begin{array}{c}\text { No DE TESES E } \\
\text { DISSERTAÇÕES }\end{array}$ \\
\hline 2003 & 0 \\
\hline 2004 & 0 \\
\hline 2005 & 2 \\
\hline 2006 & 1 \\
\hline 2007 & 2 \\
\hline 2008 & 4 \\
\hline 2009 & 4 \\
\hline 2010 & 7 \\
\hline
\end{tabular}




\begin{tabular}{c|c}
\hline ANO & $\begin{array}{c}\text { No DE TESES E } \\
\text { DISSERTAÇÕES }\end{array}$ \\
\hline 2011 & 2 \\
\hline 2012 & 5 \\
\hline 2013 & 6 \\
\hline 2014 & 2 \\
\hline TOTAL & $\mathbf{3 5}$ \\
\hline
\end{tabular}

Fonte: SILVA; REGIS; MIRANDA, 2018.

A produção discente geral levantada nessa Categoria apresenta uma elevação no número de trabalhos nos últimos anos: enquanto nos seis primeiros anos da série histórica foram defendidos 9 (nove) trabalhos, nos seis últimos anos a produção foi de 26 (vinte e seis) trabalhos. O ápice da produção foi em 2010: 7 (sete) trabalhos. Vale destacar que nos dois primeiros anos (2003 e 2004) não foram defendidos trabalhos sobre a temática no Brasil.

Tabela 2 - Distribuição das 35 teses e dissertações por universidades.

\begin{tabular}{l|c}
\multicolumn{1}{c|}{ UNIVERSIDADES } & No DE PESQUISAS \\
\hline Universidade Federal de Mato Grosso & 6 \\
\hline Universidade do Estado da Bahia & 5 \\
\hline Universidade de São Paulo & 4 \\
\hline Universidade Federal de Minas Gerais & 4 \\
\hline Universidade Federal de Pernambuco & 3 \\
\hline Pontifícia Universidade católica de São Paulo & 2 \\
\hline Universidade Federal de Alagoas & 2 \\
\hline Universidade Federal da Paraíba & 2 \\
\hline Pontificia Universidade Católica de Goiás & 1 \\
\hline
\end{tabular}




\begin{tabular}{l|c}
\hline \multicolumn{1}{c|}{ UNIVERSIDADES } & No DE PESQUISAS \\
\hline Universidade de Sorocaba & 1 \\
\hline Universidade Federal da Grande Dourados & 1 \\
\hline Universidade Estadual de Campinas & 1 \\
\hline Universidade Estadual de Maringá & 1 \\
\hline Universidade Estadual de Santa Catarina & 1 \\
\hline Universidade federal do Maranhão & $\mathbf{3 5}$ \\
\hline TOTAL & \\
\hline
\end{tabular}

Fonte: SILVA; REGIS; MIRANDA, 2018.

As universidades que apresentaram o maior número de trabalhos foram a Universidade Federal do Mato Grosso (6 trabalhos), a Universidade do Estado da Bahia (5 pesquisas), a Universidade de São Paulo e a Universidade Federal de Minas Gerais (4 trabalhos cada) (Tabela 2).

Tabela 3 - Distribuição das 35 teses e dissertações por unidades da federação.

\begin{tabular}{l|c}
\multicolumn{1}{c|}{ ESTADOS } & No DE PESQUISAS \\
\hline São Paulo & 8 \\
\hline Mato Grosso & 6 \\
\hline Bahia & 5 \\
\hline Minas Gerais & 4 \\
\hline Pernambuco & 3 \\
\hline Alagoas & 2 \\
\hline Paraíba & 2 \\
\hline Goiás & 1 \\
\hline Maranhão & 1 \\
\hline
\end{tabular}




\begin{tabular}{l|c}
\multicolumn{1}{c|}{ ESTADOS } & No DE PESQUISAS \\
\hline Mato Grosso do Sul & 1 \\
\hline Paraná & 1 \\
\hline Santa Catarina & 1 \\
\hline Total & $\mathbf{3 5}$ \\
\hline
\end{tabular}

Fonte: SILVA; REGIS; MIRANDA, 2018.

As unidades da federação que apresentaram a maior quantidade de teses e dissertações foram os estados de São Paulo, Mato Grosso, Bahia e Minas Gerais (respectivamente: 8, 6, 5 e 4 trabalhos) (Tabela 3).

Tabela 4 - Distribuição das 35 teses e dissertações por região.

\begin{tabular}{l|c}
\multicolumn{1}{c|}{ REGIÕES } & No DE PESQUISAS \\
\hline Nordeste & 13 \\
\hline Sudeste & 12 \\
\hline Centro-Oeste & 8 \\
\hline Sul & 2 \\
\hline Norte & 0 \\
\hline TOTAL & $\mathbf{3 5}$ \\
\hline
\end{tabular}

Fonte: SILVA; REGIS; MIRANDA, 2018.

A Região Nordeste se destacou com a maior quantidade de pesquisas: 13 (treze). Em seguida, aparecem Sudeste e Centro-Oeste (respectivamente, 12 e 8 trabalhos). A região Sul teve apenas 2 (dois) trabalhos. A pesquisa não conseguiu identificar trabalhos produzidos na região Norte que se encaixassem nessa categoria (Tabela 4).

O quadro descrito chama a atenção, uma vez que as regiões Sudeste e Sul 
geralmente apresentam uma maior quantidade de produções, em especial por possuírem um número mais elevado de programas de pós-graduação, com tradição na produção científica do país. Apesar de a Região Sudeste ter uma quantidade significativa de trabalhos discentes (12), ao menos nessa categoria, a Região Nordeste foi a que apresentou o maior número: 13 (treze) pesquisas. Destaque também para a Região Centro-Oeste: 8 (oito) trabalhos.

Quanto à categoria administrativa, observa-se a preponderância de trabalhos discentes defendidos em universidades públicas: 88,57\% (31 trabalhos). As privadas participaram com 11,43\% das dissertações e teses (4 pesquisas). As mulheres foram responsáveis por $65,71 \%$ da produção discente, ao passo que os homens defenderam $34,29 \%$, diferença que consideramos significativa e que representa a participação mais efetiva do gênero feminino nas pesquisas da área "Educação e Relações Étnico-Raciais".

Há um número muito maior de dissertações defendidas sobre o tema (80\%) do que de teses de doutoramento (20\%). Ou seja, de cada cinco pesquisas discentes, quatro foram dissertações de mestrado.

Tabela 5 - Distribuição das 35 teses e dissertações por período histórico estudado.

\begin{tabular}{l|c}
\multicolumn{1}{c|}{ PERÍODO HISTÓRICO } & No DE PESQUISAS \\
\hline República & 17 \\
\hline Império e República & 11 \\
\hline Império & 4 \\
\hline Colônia e Império & 2 \\
\hline Colônia & 1 \\
\hline Total & 35 \\
\hline
\end{tabular}

Fonte: SILVA; REGIS; MIRANDA, 2018.

A Categoria examinada teve a especificidade de estudar trabalhos que 
procuraram investigar aspectos relacionados à história de luta da população negra pelo direito à educação, as políticas públicas educacionais que foram confeccionadas em nosso país, as trajetórias profissionais e de vida de docentes negros(as). Devido a essa particularidade relacionada aos aspectos históricos, procurou-se construir um quadro sobre os períodos em que as produções discentes acabaram se preocupando. Dividimos os trabalhos em cinco periodizações: Colônia, Império, República e os trabalhos que gravitaram entre os períodos colonial e imperial e entre o Império e a República (Tabela 5).

O período republicano apresentou quase a metade das pesquisas (17 trabalhos ou 48,57\%). Quando comparamos com o período imperial (4 pesquisas ou 11,42\%), observamos a diferença. Entretanto, vale citar o importante número de trabalhos que destacaram suas análises sobre a Lei do Ventre Livre (1881), alguns enfocando os anos ou décadas anteriores a essa Lei, outros abordando as suas consequências. O motivo principal para que a Lei do Ventre Livre tivesse o destaque talvez seja o fato de, segundo as(os) pesquisadoras(es), ser a primeira legislação a apontar para a escolarização das crianças negras, embora as políticas públicas não tenham contemplado esse direito humano a esses filhos de escravizados(as).

Nicanor Palhares Sá (Universidade Federal do Mato Grosso) foi o orientador com o maior número de pesquisas orientadas: 4 (quatro). Em seguida, aparecem quatro professores(es) com duas pesquisas orientadas cada: Antônio Carlos Ferreira Pinheiro (Universidade Federal da Paraíba), Elisabete Conceição Santana (Universidade do Estado da Bahia), José Luis Simões (Universidade Federal de Pernambuco) e Thais Nivia de Lima e Fonseca (Universidade Federal de Minas Gerais). Outros(as) 23 (vinte e três) professoras(es) possuem uma pesquisa orientada. 


\section{EDUCAÇÃO DE CRIANÇAS E JOVENS NEGROS(AS)}

A Subcategoria 1 "Educação de Crianças e Jovens Negros(as)" abarcou as 17 pesquisas que versaram sobre as oportunidades educacionais que foram (ou não) geradas para esse público, seus processos de escolarização, as políticas públicas implementadas, a presença ou ausência de negros em instituições educacionais.

O agrupamento mostrou os obstáculos legais para a escolarização da população negra no decorrer da história brasileira, mas também retratou a luta de sujeitos negros, particularmente de familiares das crianças e jovens negros, para a garantia do acesso e permanência à escolarização. Os apontamentos da pesquisa destacaram que a população negra valorizou os processos educativos e procurou buscar formas para que seus responsabilizados, ou eles mesmos, tivessem esse direito garantido - destaque para os diversos clubes negros. Essas constatações, na maior parte dos casos, teciam críticas às tradicionais afirmações presentes na área da História da Educação, que procuravam culpabilizar os próprios sujeitos negros pela exclusão educacional, utilizando as argumentações de que eles não valorizavam os processos educacionais como a população branca.

Em linhas gerais, os trabalhos assinalaram que as políticas públicas educacionais desenvolvidas na história do Brasil não contemplaram a população negra com a amplitude e a qualidade social requeridas, deixando-a excluída ou com muita dificuldade para ser inserida ou para finalizar seus processos educacionais.

Rocha (2007), em sua dissertação intitulada “A pesquisa Cultura e educação de crianças negras em Goiás (1871-1889)”, verificou as possibilidades de inserção da criança negra na educação escolar, subsidiando-se, sobretudo, na promulgação da Lei do Ventre Livre (Lei ${ }^{0}$ 2.040, de 28 de setembro de 1871). O problema suscitado nessa pesquisa foi: as propostas educacionais que envolveram as crianças negras, em Goiás, no período de 1871-1889, foram, de fato, efetivadas ou ficaram apenas no plano legal, deixando-as à margem dos 
processos escolares? Segundo a autora (2004), na Província de Goiás, durante o período analisado, foram dois os estabelecimentos de ensino que ofereceram educação a essas crianças: a Colônia Orfanológica Blasiana e a Companhia de Aprendizes Militares. Averiguou-se que a educação oferecida se destinava à formação de mão-de-obra, pois se assentou, respectivamente, no ensino agrário e na formação militar. Na prática, a concretização do direito da criança negra à educação escolar possibilitou novas conquistas na trajetória histórica e cultural percorrida pela população negra como componentes importantes da sociedade e do povo brasileiro.

Araújo, M. L. P. de (2013) objetivou, por meio de pesquisa bibliográfica e investigação documental, estudar a escolarização das crianças negras paulistas e discutir em que medida aconteceu a disseminação da escolarização entre as camadas populares da Cidade de São Paulo no interregno 1920-1940. De acordo com a autora (2013), as crianças negras obtiveram oportunidades de escolarização quando da implementação da Escola Nova, especialmente pela intenção dos reformadores paulistas em "disciplinar" os diferentes grupos étnicoraciais que perfaziam o universo escolar, propagar os valores republicanos e reformar a vida social paulista rumo à modernidade anunciada.

Fonseca (2007) procurou pesquisar a presença de negros em escolas de Minas Gerais no período de 1820 a 1850 . Analisou, dentre outras fontes, a documentação censitária de 1831, que tentou contabilizar a população de todos os distritos mineiros e registrou as crianças que estavam nas escolas. Por meio desse registro censitário construiu um perfil racial das escolas mineiras, confrontando com informações fornecidas por outros documentos e que revelaram uma presença majoritária dos negros nos espaços voltados para os processos de educação formal. Trabalhou com o modo como a população negra de Minas Gerais era classificada por meio de diferentes terminologias (pretos, pardos, crioulos, cabras), que demarcavam proximidades e distâncias com o mundo da escravidão. Considerou que a presença dos negros nas escolas mineiras revela que esta instituição era um dos elementos acionados por este grupo com o 
objetivo de afirmação no espaço social. Constatou um predomínio absoluto de negros em meio aos indivíduos que foram registrados em escolas primárias. Tal interpretação vai de encontro ao exposto pela historiografia educacional, que sempre mencionou a escola como uma instituição com a qual os negros estabeleceram contatos esporádicos ou casuais. Fonseca (2007) afirma que a historiografia continua desconsiderando os negros enquanto sujeitos da escolarização, sendo falso o entendimento de que os negros não valorizavam os processos de escolarização e, por isso, ficavam marginalizados - essa análise historiográfica tradicional, em decorrência, contribuiria para a invisibilidade dos sujeitos negros, sobretudo por colocá-los como os próprios responsáveis pela exclusão educacional do qual foram vítimas.

Portela (2012) estudou as iniciativas de atendimento de crianças livres no período de 1871 a 1888 na província de São Paulo, procurando investigar a trajetória das crianças que foram entregues ao Estado. Realizou um levantamento e um estudo da produção discente sobre a escolarização das crianças negras em diversas regiões ou províncias do Brasil. Revelou a ausência de números sobre as crianças negras livres, bem como a inexistência de instituições voltadas para o seu atendimento na província de São Paulo, ao contrário do que se encontra em outras províncias do Império brasileiro. Segundo a autora (2012, p. 154),

[...] a província de São Paulo foi omissa em relação ao atendimento das crianças negras, não apenas por mantê-las nas fazendas após o período determinado pela lei, por suprimir o direito dessas crianças em acompanhar suas mães libertas, mas principalmente por relegá-las a um lugar de invisibilidade e por perpetuar esse abandono por um longo tempo.

Sebrão (2010) procurou compreender o processo de escolarização de africanos e afrodescendentes na Freguesia de Nossa Senhora do Desterro (SC), de 1870 a 1888. A pesquisa exibe elementos sobre a instrução popular e sobre as possibilidades que as populações de origem africana poderiam vislumbrar nas políticas voltadas à educação para os pobres. Apresenta, ainda, o movimento 
complexo de presença ou ausência, em que experiências da presença de africanos e afrodescendentes em escolas coexistem com um processo de ausência, em um sentido de invisibilidade, com um "apagamento de seus rastros" nas representações engendradas. A perversidade do "apagamento de seus rastros" não foi aceita passivamente, pelo contrário, houve um movimento de resistência e subversão por parte das populações africanas. Cita como exemplo a trajetória educacional do poeta simbolista Cruz e Souza: seus pais foram escravizados, mas arrumaram brechas nas leis para matricular seus filhos, prova de que as classes populares e a população negra não desprezavam a formação escolar. A título de recomendação, realça que a configuração de invisibilidade da população negra é gerada pelas representações engendradas que legitimam concepções universalistas que ratificam o apagamento de seus rastros: "Daí a importância de [os pesquisadores] mobilizar[em] as fontes e transitar[em] por enigmas que problematizem as representações" (SEBRÃO, 2010, p. 107, destaques nossos).

Xavier (2012) estudou o processo educacional de crianças de diferentes pertencimentos social e étnico-racial em Mato Grosso, mais precisamente na cidade de Cuiabá, no período de 1870 a 1890 . Procurou dar visibilidade à experiência educacional de diferentes crianças, de modo a destacar a pluralidade de seus pertencimentos social e étnico-racial, assim como as formas e os espaços educativos existentes na época. Além da instituição escolar, quais foram os possíveis espaços e estratégias educativas vivenciadas pelas crianças em idade escolar em Cuiabá? Teve como base um conjunto documental e três estudos de caso que incluem experiências escolar e não escolar. Verificou-se que a composição étnico-racial e as relações sociais em Mato Grosso, no século XIX, eram muito ricas e complexas. Apreendeu-se a lenta dinâmica de afirmação da escola como espaço privilegiado de formação das novas gerações, no diálogo e tensão com outros espaços e estratégias educativas. Ressaltou-se, entretanto, que não foi possível reconstituir o percurso individual de um ou mais sujeitos negros, apesar de constatar suas presenças no ambiente escolar da época.

Ramos (2008) ambicionou entender qual foi a finalidade da educação das 
crianças nascidas do ventre escravo numa época em que o número de escolas era diminuto até mesmo para a população livre, e cujo acesso era restrito às camadas mais privilegiadas da população. Seu estudo focou na Região de Campinas, mas também acabou alargando o olhar para outras localidades provinciais do Império (180o a 1888). Portanto, o objeto investigado é o contexto das mudanças da sociedade brasileira do século XIX, no qual emergiu a Lei do Ventre Livre de 1871. De acordo com a autora (2008), essa Lei contemplou aspectos da educação das crianças nascidas livres do ventre escravo. A propalada educação seria um fator de integração social dos negros, com uma gradual abolição da escravatura. A educação constituiria, em teoria, uma preocupação por parte do Império, sob o viés de ser uma das condições para a eliminação do trabalho escravo. A Lei do Ventre Livre idealizava uma educação para as crianças que nasceriam livres, uma vez que proporcionaria às novas gerações de negros livres a condição para fazerem parte da sociedade brasileira. Porém, a educação das crianças negras, na prática, não passava de uma mera intenção, pois sem muitos interesses na sua concretização, visto que a escola, naquele período, era um privilégio, uma oportunidade para poucos. Por outro lado, constatou-se que para a população negra cativa do período se colocavam necessidades mais prementes, dentre elas a da própria sobrevivência. Apesar dos resultados alcançados na pesquisa, Ramos (2008) ressalta que há a necessidade de se realizar levantamentos nos asilos para órfãos, nas associações encarregados de cuidar da infância desvalida, orfanatos de várias províncias da época, para se obter indícios mais contundentes de que muitas crianças negras também tiveram o mesmo destino de exclusão de muitas crianças pobres.

Silva, V. M. da (2013) estudou a presença ou ausência de escravizados e criados nas escolas noturnas de primeiras letras na Província do Paraná (18721888). Procurou analisar os sentidos e contextos do regime escravocrata no século XIX, principalmente no que se coaduna às décadas finais da escravidão, importante período dos encaminhamentos político-sociais da crise da escravidão em todo o Império. A partir da análise das fontes consultadas, o autor concluiu que os dados encontrados na pesquisa, de certa forma, ressignificaram a 
historiografia do negro na educação no Paraná, no século XIX, permitindo evidenciar outros sentidos, que não estão frequentemente abordados nas literaturas até então existentes, de que os escravos tiveram acesso à instrução formal, ou seja, frequentaram escolas no Paraná, nas décadas de 1870 e 1880. Como recomendação, o autor (2013) enfatizou que as divergências acerca dos sentidos da escravidão na historiografia brasileira lançam as bases para se constituir alguns princípios e interpretações que vão ganhando espaços no campo da pesquisa. Seria necessário rever as limitações dos estudos que observam a escravidão como algo absolutamente rígido ou ainda aquelas narrativas em que destacam o heroísmo épico da rebeldia.

Arantes teve duas pesquisas analisadas $(2005,2014)$. Em sua tese de doutorado (2014), estudou as práticas de racialização às quais os alunos dos grupos escolares foram submetidos em Pernambuco, as repercussões do pensamento higienista e eugênico que foram processados no âmbito da organização escolar pública, com foco na cidade de Recife. Nesse processo, verificou-se a ocorrência da racialização das ideias, que se desdobraram no cotidiano escolar para o estabelecimento do biótipo do escolar pernambucano, procurando "oferecer bases científicas (antropométricas e higiênicas) para a constituição de turmas homogêneas intelectual e fisicamente” (2014, p. 232). Constatou-se que a cultura escolar colaborou para estabelecer as chamadas distinções raciais, com o propósito de assegurar o progresso do país, formando cidadãos saudáveis, regenerados e civilizados. Debateu o papel que a disciplina de educação física teve no cenário brasileiro e local tendo em vista que as políticas de racialização, que tiveram como base testes e medições antropométricas, imprimiram a missão de revigorar a raça e garantir o estabelecimento de uma sociedade saudável física, intelectual e moralmente. Finalizou seu estudo afirmando que as práticas de racialização estiveram presentes em praticamente todas as políticas educacionais no período em estudo e tiveram como campo experimental os grupos escolares.

Em sua dissertação de mestrado, Arantes (2005) analisou a educação, a 
instrução e os possíveis destinos pensados para os meninos negros, brancos e índios na Colônia Orfanológica Isabel, instituição criada pelos Missionários Capuchinhos, com o objetivo de receber crianças órfãs e ingênuas, na segunda metade do séc. XIX, na província de Pernambuco. Apurou que, conquanto a Colônia tivesse sido criada com o intuito de atender as crianças "ventre-livre", conforme previsão da lei de 1871, esse não foi o principal público da instituição: "O Estado Imperial parece, assim, não ter cumprido a própria lei que engendrou no interior dos debates em torno da libertação dos escravos" (2005, p. 193-194). Apesar disso, a Colônia Isabel significou uma possibilidade de recolhimento e instrução para órfãos ingênuos, libertos e índios, grupos excluídos no período. A instituição produziu professores, profissionais liberais, caixeiros, funcionários públicos e até um Bacharel em Direito, mas a maioria dos colonos Isabel dedicouse à música, considerada, na época, uma profissão manual. Segundo a autora (2005), outras questões poderiam ser respondidas em futuras pesquisas: quantos colonos Isabel teriam se tornado profissionais liberais, professores, funcionários públicos? Que conteúdos passaram a ser ensinados?

Barros (2005) realizou uma pesquisa histórica sobre o processo de escolarização da população negra na cidade de São Paulo entre 1870 e 1920, período de vigência do entusiasmo pela educação. Analisou a inserção educacional e a atuação da população negra na busca pelo acesso à escolarização. Contatou-se, a partir de Registros da instrução pública coletados no Arquivo do Estado de São Paulo, a presença de estudantes negros nas escolas paulistanas. Mas, no momento em que se relaciona essa presença com depoimentos de pessoas de origem negra que vivenciaram a escolarização na época e de profissionais envolvidos com a instrução pública no período (professores, inspetores de ensino), averígua-se que a presença das crianças negras na escola gerava um "incômodo", existindo uma série de práticas geradas pelo sistema escolar que no mínimo dificultava a presença desses estudantes. Ou seja, o acesso à escola acontecia de maneira diferente e desigual entre a população negra e a população branca. A autora (2005) trabalhou, ainda, com as trajetórias de vida do advogado e abolicionista Luiz Gama e do professor da Academia de Direito 
José Rubino de Souza, negros que alcançaram elevadas posições dentro da cultura letrada. Para ela, esses intelectuais devem ser citados não como casos excepcionais, mas que se inscreviam nos movimentos mais amplos da população negra que buscava a escolarização. Porém, constatou em registros, como em depoimentos e em jornais de entidades negras do período, que uma parte desse grupo social ficou à parte de tal movimento, não se manifestando no sentido de interesse e busca pela escola, o que se constitui na outra vertente da ação negra. Portanto, assim como a ação branca, a posição da população negra não pode ser entendida como um bloco fechado, muito pelo contrário: a escolarização era também para os negros um campo de tensões e embates. Acrescenta-se a isso o fato de as elites brancas não terem como grande objetivo proibir que os negros conseguissem ter acesso à instrução.

Souza (2010) buscou evidenciar, por meio de levantamento das fontes documentais no Arquivo Público de Mato Grosso (APMT), a presença, a permanência e as oportunidades oferecidas aos jovens negros nas instituições de ensino da cidade de Cuiabá-MT, durante a Primeira República. Apontou para a compreensão de que o processo de integração dos negros no cenário educacional não aconteceu no sentido de promovê-los socialmente ou de incorporá-los ativamente em uma sociedade que se pretendia democrática e pregava um discurso transformador. Pelo contrário, constituíram-se estratégias que previam a sua entrada lenta no movimento civilizatório e a sua contínua subordinação ao grupo social dominante. Os jovens negros estiveram presentes no processo de formação da nova nação brasileira, entretanto, não foi proporcionado a eles condições efetivas para ascenderem à condição de aluno, sobrando apenas a opção de servirem de mão-de-obra livre, submissos, conforme interesses do mercado. A autora (2010, p. 128) recomenda que, pelo fato de existirem poucas produções referentes a esse assunto, é necessário que o tema seja mais explorado.

Miranda (2010) realizou uma pesquisa de cunho histórico documental e bibliográfico que teve por objetivo verificar a presença de crianças negras na Instrução Pública em Mato Grosso, mais precisamente em Cuiabá, entre os anos 
de 1870 e 1890 . Averiguou que o número de crianças negras frequentando as escolas públicas de Cuiabá era expressivo no que tange ao número de crianças brancas. Concluiu que não era proibido o ingresso de crianças negras nas instituições educacionais, entretanto, o número destas fora da escola ainda era muito superior ao de crianças brancas. A autora (2010) teve acesso aos registros de crianças negras que trabalhavam, o que a fez acreditar ser este um dos motivos que as afastavam da escola. Em relação ao período que precedeu a Abolição, pressupunha-se que os escravizados estavam alheios à instrução, mas a documentação estudada mostra que algumas mães se preocupavam com a educação de seus filhos. Em suma, as crianças negras estavam frequentando a Instrução Pública Primária em Cuiabá, porém, tal verificação não é sinônima de que a educação era realmente para todos e, muito menos, que o preconceito estava ausente nas relações cotidianas escolares.

A influência do racismo na educação mato-grossense, na transição do século XIX ao XX, foi o objeto de estudo de Cruz, P. D. R. da (2009), que investigou, ainda, a forma como as concepções racistas europeias influenciaram o campo educacional e a instrução pública primária em Mato Grosso, condicionando a constituição da percepção social de povo e de nação e influenciando instituições de pesquisa e de ensino, sobretudo as escolas primárias. A elite dirigente tinha como pressuposto uma visão racista da realidade, o que a fez desenvolver um sistema escolar indutor de um processo civilizatório discriminatório em relação a negros, pardos e brancos pobres, especialmente ao distinguir o conhecimento europeu ocidental como categoria superior em detrimento de todas as outras formas de produção de conhecimento. O autor (2009) demonstrou que a escola pública primária em Mato Grosso foi criada a partir de concepções racistas que negaram aos negros, pardos e pobres a condição que nos caracteriza como seres humanos, a saber: a capacidade de produzir cultura e a capacidade de imaginar e de sonhar.

Marques (2012) apresentou os resultados da pesquisa que versou sobre a presença de alunos negros no ensino profissionalizante, em Cuiabá/MT, período 
da Primeira República. Evidenciou que os estudantes negros e mestiços pobres que ingressaram nas instituições profissionalizantes tinham-nas como alternativa para adquirir os conhecimentos práticos que possibilitassem sua inserção no mercado de trabalho. $\mathrm{O}$ acesso a esses cursos profissionalizantes tinha como meta governamental evitar a ociosidade e desviar os jovens do crime. Matricular-se nas escolas profissionalizantes talvez não fosse a primeira escolha das famílias e dos jovens, mas sim a única oportunidade que eles teriam de se alfabetizarem e terem um ofício para ingressar no mercado de trabalho em Cuiabá e regiões próximas. O ingresso nas escolas profissionalizantes era considerado uma possibilidade de aprender uma profissão e se inserir no mercado de trabalho, como proprietário ou empregado das oficinas.

A escolarização da população negra em Alagoas foi o tema de pesquisa de Santos (2009), em especial as particularidades históricas no período de 1840 a 1890. Procurou saber que tipo de educação era ministrado e conhecer as razões pelas quais se ofertava tal tipo de formação. O sistema público de ensino alagoano, mesmo com o total abandono em que se encontrava, atendia aos negros livres. Averiguou que, após a Lei do Ventre Livre, de 1871, os escravizados puderam frequentar os cursos noturnos, e os menores que foram emancipados por essa Lei conseguiram ter acesso às letras por meio da Escola Central. Também pôde constatar que o ensino oferecido a esse grupo social objetivava a pretensa civilização nos costumes e comportamentos, bem como a educação para o trabalho. A autora ressaltou que não foi possível saber quais foram os espaços para a alfabetização dos escravizados no período anterior à década de 1870. Devido às restrições, em virtude das leis que os proibiam de frequentar os espaços de ensino, possivelmente foram alfabetizados em espaços domésticos. Todavia, verificou que esse segmento tão marginalizado da população, apesar dos preconceitos existentes, foi contemplado com o direito à escolarização por meio das aulas noturnas, a partir de 1875. A permissão para essa entrada estava acoplada à promulgação da Lei do Ventre Livre, de 1871. Os segmentos dominantes da sociedade achavam que a população negra que seria libertada com o fim da escravidão no Brasil deveria ser educada para o trabalho livre, e para 
viverem como livres, pois eram discriminados e considerados portadores de comportamentos desprezíveis para uma sociedade que tinha como paradigma de civilização a Europa. A conclusão do trabalho é a de que a escola pública de Alagoas foi desenvolvida para atender a população pobre, sendo frequentada por negros, sobretudo por aqueles classificados como pardos - os de pele mais escura estavam menos presentes, o que levou à hipótese de que estes últimos sofriam dos profundos estigmas.

O estudo sobre as relações sociais das meninas negras no Asilo de Santa Teresa (MA), a partir da escolarização recebida nesta instituição foi desenvolvido por Araújo, C. S. (2013). A partir de um cenário social imerso em acontecimentos históricos marcantes como a Lei do Ventre Livre e a Abolição da Escravatura, traçou um caminho de análise que abrangeu o cenário nacional dos asilos no Brasil, além de pontuar como acontecia o processo de instrução de negros na segunda metade do século XIX. Realizou uma discussão de gênero e etnia, tentando compreender como aconteciam as relações sociais entre as meninas negras e as meninas brancas dentro da instituição em estudo, bem como procurou compreender como o critério cor interferiu na escolarização das meninas negras. O Asilo de Santa Teresa, localizado em São Luís/MA, foi uma das instituições mais importantes do período e atendia meninas pobres e desvalidas.

\section{ANÁLISE SOBRE O CONJUNTO DOS TRABALHOS}

Por se tratarem de pesquisas que versam sobre a História da Educação da População Negra, há uma preponderância de pesquisas de cunho histórico documental, discussões sobre a historiografia construída na área, levantamentos bibliográficos mais aprofundados ou que utilizaram a História Oral para analisar a memória individual ou coletiva construída pela população negra.

Apesar de os trabalhos serem da área de Educação, os(as) autores(as) mais utilizados(as) são mais específicos da área da História: Michel de Certeau e 
suas formas metodológicas de escritas na História; Roger Chartier e suas colaborações sobre "práticas" e "representações"; Sidney Chalhoub, especialmente suas análises sobre o período da escravidão, o cotidiano e as lutas para a liberdade nas décadas anteriores à promulgação da Lei Áurea; Pierre Bourdieu e seus estudos de campo, habitus e capital; Norbert Elias e suas contribuições para a construção do pensamento histórico e da teoria sociológica; Circe Bittencourt e suas análises sobre livros ou manuais didáticos; Marcos Vinicius Fonseca, no que tange aos estudos sobre a presença ou ausência de crianças negras na educação brasileira no século XIX.

Petronilha Beatriz Gonçalves e Silva e Kabengele Munanga são os mais citados no momento em que os(as) pesquisadores(as) debatem as reivindicações coletivas negras e as condições de vida da população negra, sobretudo no tocante ao acesso e permanência na educação.

Muito provavelmente devido ao fato de $80 \%$ dos trabalhos analisados serem dissertações de mestrado, há uma ocorrência maior de estudos de caso. É necessário salientar, entretanto, a busca de muitas(os) pesquisadoras(es) em realizarem um levantamento bibliográfico consistente sobre a discussão da temática que tratavam.

Não há a ocorrência de um tema que possa ser considerado como emergente, ou seja, que tenha tido maior presença nas pesquisas desenvolvidas nos últimos cinco anos da pesquisa.

Em relação à subcategoria "Educação de crianças e jovens negros(as)", salientamos a ênfase dada pelas(os) pesquisadoras(es) à presença de crianças e jovens negros na educação formal, apesar de frequentarem escolas cuja qualidade social deixava a desejar, justamente pelo descaso dos poderes públicos.

As recomendações dos trabalhos discentes são muito genéricas ou apenas apontam para a continuidade do seu foco ou eixo de pesquisa. Apesar do número elevado de teses e dissertações encontradas e analisadas - o que demonstra ser uma área em expansão -, nota-se que a temática da História da Educação da 
População Negra ainda é uma área em construção e com necessidade de mais pesquisas, uma vez que abarca um período histórico amplo e uma população que foi e continua sendo maioria na sociedade brasileira.

A produção de conhecimento na área colabora em muitos aspectos, entre eles: 1) o combate a epistemologias cujas matrizes são discriminatórias ou pouco diversas; 2) o combate a práticas preconceituosas e discriminatórias ocorridas nas relações interpessoais e a conteúdos eurocêntricos dos materiais didáticos, que desmerecem a História e a Cultura Africana e Afro-Brasileira; 3) a confrontação em relação às situações de racismo, de preconceito racial e de discriminação racial no cotidiano escolar, quer na educação básica, quer no ensino superior7.

Os livros didáticos têm aumentado o espaço destinado à História da África, à Cultura Afro-brasileira e à História dos Povos Indígenas, porém, isso não tem significado uma substancial alteração nas perspectivas sobre a História do Brasil. Mentalidades retrógradas continuam presentes nessas obras: a) os africanos, os negros e indígenas permanecem como personagens subalternos, coadjuvantes; b) a África e a América antes da conquista são percebidos como espaços sem história; c) a perspectiva eurocêntrica se mantém em destaque (COELHO; COELHO, 2018).

Munanga (2015) afirma que todas as ideologias de dominação tentaram falsificar e aniquilar as histórias dos povos que dominaram; a historiografia colonial negou a história do continente africano e, quando muito, contou-a a partir do ponto de vista do colonizador, estratégia similar à ocorrida com a história do negro no Brasil, negada ou narrada sob a ótica do outro e de seus interesses.

Cabe ressaltar que a denominação dessa Categoria também não é ponto concordante: a maior parte das pesquisas abaliza de forma mais direta ou mais

\footnotetext{
7 Para a realização de diagnósticos e a construção de planos de ação para o combate ao racismo nas unidades da educação básica, ver "Indicadores da Qualidade na Educação: Relações Raciais na Escola" (CARREIRA; SOUSA, 2013).
} 
sútil a necessidade no trato da especificidade da História da Educação da População Negra com a argumentação de que a área da História da Educação brasileira, histórica e majoritariamente, não considerou a importância no trato dessa questão. Porém, algumas teses e dissertações examinadas não destacaram o imperativo dessa especificidade ou mesmo concluíram que este recorte não deva ser construído ao largo da grande área História da Educação brasileira, justamente porque ainda não haveria uma produção consistente para essa separação.

\section{CONSIDERAÇÕES FINAIS}

Em linhas gerais, podemos sublinhar que o conjunto das pesquisas tem o mérito de discutir temas que foram desconsiderados nas produções educacional e histórica brasileiras, talvez mais na primeira do que na segunda. Observa-se uma disposição de (não só, mas principalmente) pesquisadoras(es) negras(os) em examinar essas histórias, essas memórias, essas lutas, essas trajetórias de vida construídas pela população negra que foram desprezadas ou ocultadas na ciência brasileira, mas costumeiramente reivindicadas pelo movimento negro. Os negros sempre lutaram por maiores espaços de poder, mais oportunidades sociais e educacionais, sobretudo nos últimos anos, como bem demonstram os trabalhos estudados. E isso é muito importante. É justiça a ser feita, são espaços democráticos que estão sendo reivindicados e criados, apesar de toda discriminação racial presente nesse país. Esse é certamente o discurso mais consolidado no conjunto dos trabalhos.

O direito a uma educação antirracista deve continuar no radar do movimento negro e de todas(os) aquelas(es) que lutam pela igualdade racial:

[...] todos que investigam e/ou militam no campo das relações étnicoraciais e educação também concordam que [...] é preciso efetivar uma educação que se posicione publicamente contra o racismo. Por isso, os 
Quanto às lacunas visualizadas no conjunto dos trabalhos, por tratar-se de uma periodização histórica enorme, que se inicia com a chegada dos africanos sequestrados e escravizados ao Brasil indo até os anos mais recentes, concluímos que fica difícil apontar as épocas que necessitam de mais estudos. O que podemos destacar é que pelo menos dois períodos e/ou eventos históricos tiveram um número mais considerado de pesquisas: a Lei do Ventre Livre e a Primeira República. Observam-se estudos em que o objetivo principal foi perscrutar a história de vida ou as proposições de intelectuais, docentes ou coletivos negros, o que é muito respeitável.

Faltaram pesquisas que permitissem analisar as vontades e desejos citados diretamente por estudantes negros(as) - crianças, adolescentes ou jovens -, apesar de reconhecermos a dificuldade de se realizar estudos históricos com essa dimensão. Não presenciamos um número considerável de investigações que tivesse como foco as reivindicações da população negra em períodos mais recentes da história brasileira, como a partir da segunda metade do século XX. Pensamos que há uma necessidade de estudos mais vigorosos que se debrucem sobre os pontos de pauta mais generalizados que marcaram o movimento negro nos seguintes períodos: Ditadura Empresarial-Militar de 1964-1985; período constituinte; exigências do movimento negro na discussão em torno da Lei de Diretrizes e Bases da Educação Nacional, iniciada a partir da promulgação da Constituição Federal de 1988 e concluída em 1996 (Lei no 9.394); pontos convergentes do movimento negro nos debates do Plano Nacional de Educação, em especial na proposta construída pelos movimentos sociais e sindicatos/associações ligados à educação (Plano Nacional de Educação Proposta da Sociedade Brasileira), consolidada no II Congresso Nacional de Educação 
(Belo Horizonte, 1997), entre outros. Abordagens mais específicas ou interseccionais que tenham recortes étnico-raciais sobre gênero, orientação sexual, juventude, população camponesa também são imprescindíveis.

\section{REFERÊNCIAS}

ARAÚJO, Claudiane Santos. Infância negada: um estudo sobre as relações sociais de meninas negras no Asilo de Santa Teresa (1855-1870). $2013.82 \mathrm{f}$. Dissertação (Mestrado em Educação) - Centro de Ciências Sociais, Universidade Federal do Maranhão, São Luís, 2013. Disponível em:

http://tedebc.ufma.br:808o/jspui/handle/tede/255. Acesso em: 10 ago. 2016.

ARAÚJO, Marcia Luiza Pires de. A escolarização de crianças negras paulistas (1920-1940). 2013. 202 f. Tese (Doutorado em Educação) Faculdade de Educação, Universidade de São Paulo, São Paulo, 2013. Disponível em: https://www.teses.usp.br/teses/disponiveis/48/48134/tde-27062013124505/publico/MARCIA_LUIZA_PIRES_DE_ARAUJO_rev.pdf. Acesso em: 10 ago. 2016.

ARANTES, Adlene Silva. O papel da Colônia Orfanológica Isabel na educação e na definição dos destinos de meninos negros, brancos e índios na Província de Pernambuco (1874-1889). 2005. 211 f.

Dissertação (Mestrado em Educação) - Centro de Educação, Universidade Federal de Pernambuco, Recife, 2005. Disponível em:

http://repositorio.ufpe.br/bitstream/handle/123456789/4668/arquivo5737_1. pdf? sequence=1\&isAllowed=y. Acesso em: 10 ago. 2016.

ARANTES, Adlene Silva. Processos de racialização nas escolas primárias pernambucanas (1911-1945). 2014. 255 f. Tese (Doutorado em Educação) - Faculdade de Educação, Centro de Educação, Universidade Federal da Paraíba, João Pessoa, 2014. Disponível em:

http://tede.biblioteca.ufpb.br/handle/tede/4802. Acesso em: 10 ago. 2016.

BARROS, Surya Aaronovich Pombo de. Negrinhos que por ahi andão: a escolarização da população negra em São Paulo (1870-1920). 2005. 185 f.

Dissertação (Mestrado em Educação) - Faculdade de Educação, Universidade de São Paulo, São Paulo, 2005. Disponível em:

http://www.usp.br/niephe/publicacoes/docs/_disserta\%C3\%A7\%C3\%A3o-empdf.pdf_.pdf. Acesso em: 10 ago. 2016. 
CARREIRA, Denise; SOUZA, Ana Lúcia Silva Souza. Indicadores da Qualidade na Educação: relações raciais na escola. São Paulo: Ação Educativa, 2013.

COELHO, Mauro Cezar; COELHO, Wilma de Nazaré Baía. As Licenciaturas em História e a Lei 10.639/o3: percursos de formação para o trato com a diferença? Educação em Revista, Belo Horizonte, v. 34, e192224, 2018.

CRUZ, Paulo Divino Ribeiro da. A influência do racismo na educação mato-grossense na transição do século XIX ao XX. 2009. 172 f. Dissertação (Mestrado em Educação) - Instituto de Educação, Universidade Federal de Mato Grosso, Cuiabá, 2009. Disponível em:

http://livroso1.livrosgratis.com.br/cpo87784.pdf. Acesso em: 10 ago. 2016.

FONSECA, Marcus Vinicius. Pretos, pardos, crioulos e cabras nas escolas mineiras do século XIX. 2007. 256 f. Tese (Doutorado em Educação) - Faculdade de Educação, Universidade de São Paulo, São Paulo, 2007. Disponível em:

http://www.teses.usp.br/teses/disponiveis/48/48134/tde-08112007143618/pt-br.php. Acesso em: 10 ago. 2016.

GOMES, Nilma Lino. Apresentação. In: SILVA, Paulo Vinicius Baptista da; REGIS, Kátia; MIRANDA, Shirley Aparecida de. Educação das relações étnico-raciais: o Estado da Arte. Curitiba: NEAB-UFPR; ABPN, 2018.

GOMES, Nilma Lino. Relações étnico-raciais, educação e descolonização dos currículos. Currículo sem Fronteiras, v. 12, n. 1, p. 98-109, jan./abr. 2012.

GOMES, Nilma Lino; ARAÚJO, Marlene de. Estudo teórico sobre infância, educação infantil e relações étnico-raciais: alguns pontos para pensar a Infância de 0 a 5 anos. In: COELHO, Wilma de N. B. et al. (org.). A Lei no 10639/2003: pesquisas e debates. São Paulo: Editora Livraria da Física, 2014. p. $223-277$.

MARQUES, Zilma Maria Silva. Presença de alunos negros no Ensino Profissionalizante na Primeira Republica em Cuiabá. 2012. 119 f. Dissertação (Mestrado em Educação) - Instituto de Educação, Universidade Federal de Mato Grosso, Cuiabá, 2012. Disponível em:

http://www.ie.ufmt.br/ppge/dissertacoes/index.php?autor_nome=\&ano_base =\&palavra_chave=\&orientador=";"http://www.ie.ufmt.br/ppge/dissertacoes/in dex.php?autor_nome=\&ano_base=\&palavra_chave $=\&$ orientador. Acesso em: 10 ago. 2016.

MIRANDA, Mary Diana da Silva. Crianças negras na Instrução Pública 
em Cuiabá/MT (1870-1890). 2010. 81 f. Dissertação (Mestrado em Educação) - Instituto de Educação, Universidade Federal de Mato Grosso, Cuiabá, 2010. Disponível em:

www.ie.ufmt.br/ppge/dissertacoes/index.php?autor_nome=\&ano_base=\&pala vra_chave=\&orientador. Acesso em: 10 ago. 2016.

MUNANGA, Kabengele. Por que ensinar a história da África e do negro no Brasil de hoje? Revista do Instituto de Estudos Brasileiros: São Paulo, n. 62, p. 20-31, dez. 2015.

OLIVEIRA, Fabiana. Um estudo sobre a creche: o que as práticas educativas produzem e revelam sobre a questão racial? 2004. Dissertação (Mestrado em Ciências Humanas) - Universidade Federal de São Carlos, São Carlos, 2004.

PORTELA, Daniela Fagundes. Iniciativas de atendimento para crianças negras na província de São Paulo (1871-1888). 2012. 169 f. Dissertação (Mestrado em Educação) - Faculdade de Educação, Universidade de São Paulo, São Paulo, 2012. Disponível em: http://www.teses.usp.br/teses/disponiveis/48/48134/tde-04072012103153/pt-br.php. Acesso em: 10 ago. 2016.

RAMOS, Claudia Monteiro da Rocha. A escravidão, a educação da criança negra e a lei do ventre livre (1871): a pedagogia da escravidão. 2008. 215 f. Dissertação (Mestrado em Educação). Universidade Estadual de Campinas, Campinas, 2008. Disponível em:

http://www.bibliotecadigital.unicamp.br/document/?code=vtlso00436701\&opt =1. Acesso em: 10 ago. 2016 .

ROCHA, Fernanda Franco. Cultura e educação de crianças negras em Goiás (1871-1889). 2007. 120 f. Dissertação (Mestrado em Educação) Pontifícia Universidade Católica de Goiás, Goiânia, 2007. Disponível em: http://tede.biblioteca.ucg.br/tde_busca/arquivo.php?codArquivo=401";"http:/ /tede.biblioteca.ucg.br/tde_busca/arquivo.php?codArquivo=401. Acesso em: 10 ago.2016.

ROSEMBERG, Fúlvia. A criança pequena e o direito à creche no contexto dos debates sobre infância e relações raciais. In: BENTO, Maria A. C. (org.)

Educação Infantil, igualdade racial e diversidade: aspectos políticos, jurídicos, conceituais. São Paulo: CEERT, Ufscar, MEC, 2011.

SANTOS, Mônica Luise. A escolarização de negros: particularidades históricas de Alagoas (1840-1890). 2009. 148 f. Dissertação (Mestrado em 
Educação) -Universidade Federal de Alagoas, Maceió, 2009. Disponível em: http://www.ufal.edu.br/unidadeacademica/cedu/pos-graduacao/mestrado-edoutorado-em-educacao/dissertacoes/2009/monica-luise-santos/view. Acesso em: 10 ago.2016.

SEBRÃO, Graciane Daniela. Presença/ausência de africanos e afrodescendentes nos processos de escolarização em Desterro Santa Catarina (1870-1888). 2010. 137 f. Dissertação (Mestrado em Educação) - Centro de Ciências Humanas e da Educação, Universidade Estadual de Santa Catarina, Florianópolis, 2010. Disponível em:

http://www.tede.udesc.br/tde_arquivos/17/TDE-2010-05-18T140303Z740/Publico/graciane.pdf. Acesso em: 10 ago. 2016.

SILVA, Paulo Vinicius Baptista da; REGIS, Kátia; MIRANDA, Shirley Aparecida de. Educação das relações étnico-raciais: o Estado da Arte. Curitiba: NEAB-UFPR; ABPN, 2018.

SILVA, Petronilha Beatriz. Gonçalves. e. Crianças negras entre a assimilação e a negritude. Revista Eletrônica de Educação, São Carlos, v. 9, n. 2, p. 161187, 2015.

SILVA, Vicente Moreira da. Escravos e criados nas escolas noturnas de primeiras letras na Província do Paraná (1872-1888). 2013. 276 f. Dissertação (Mestrado em Educação) - Centro de Ciências Humanas, Letras e Artes, Universidade Estadual de Maringá, Maringá, 2013. Disponível em: http://www.ppe.uem.br/dissertacoes/2013\%20-\%20Vicente.pdf. Acesso em: 10 ago. 2016.

SOUZA, Carla Patrícia Marques de. Os jovens negros e a educação em Cuiabá (1889-1910). 2010. 139 f. Dissertação (Mestrado em Educação) Instituto de Educação, Universidade Federal de Mato Grosso, Cuiabá, 2010. Disponível em: http://livroso1.livrosgratis.com.br/cp149982.pdf. Acesso em: 10 ago. 2016.

XAVIER, Ana Paula da Silva. Processos educativos da infância em Cuiabá (1870-1890). 2012. 195 f. Tese (Doutorado em Educação Conhecimento e Inclusão Social) - Faculdade de Educação, Universidade Federal de Minas Gerais, Belo Horizonte, 2012. Disponível em: http://www.bibliotecadigital.ufmg.br/dspace/handle/1843/BUOS-92XR4H. Acesso em: 10 ago.2016. 
MARCELO PAGLIOSA CARVALHO é doutor em Educação pela Universidade de São Paulo (USP). Professor Associado da Universidade Federal do Maranhão (UFMA). Pesquisa executada com o financiamento da Secadi/MEC (Secretaria de Educação Continuada, Alfabetização, Diversidade e Inclusão do Ministério da Educação) e da Fundação Araucária de Apoio Científico e Tecnológico do Estado do Paraná e com o apoio institucional da Universidade Federal de Minas Gerais (UFMG), Universidade Federal do Maranhão (UFMA) e Universidade Federal do Paraná (UFPR).

E-mail: marcelo.pagliosa@yahoo.com.br

(i) http://orcid.org/0000-0002-2498-525X

Recebido em: 27 de outubro de 2019

Aprovado em: 23 de março de 2020

Revista História da Educação - RHE

Associação Sul-Rio-Grandense de Pesquisadores em História da Educação - Asphe

Artigo de acesso aberto distribuído nos termos de licença Creative Commons. 